\title{
Em busca da eqüidade de gênero
}

\section{A questão de gênero no Brasil.}

PENA, Maria Valério J unho; CORREIA, Ma ria C.; VAN BRONKHORST, Bemice.

Rio de J a neiro: Gráfic a O Luta dor, 2005. $171 \mathrm{p}$.

A questão de gênero no Brasil é um rela tório que reúne dados e conclusões sobre algumas das questões relacionadas a gênero no país. Publicado em 2005, é uma versão que a tualiza informações recolhidas em 1999 e publicadas pela primeira vez em 2003. Com patrocínio do Banco Mundial e tendo como colaboradores representantes do govemo brasileiro e da Cepia (Cidadania Estudo Pesquisa Informação e Ação), esse documento é de inteira responsabilidade de suas a utoras - Maria Va lério J unho Pena, cientista soc ial líder do Departa mento de Desenvolvimento Ambiental e Social Sustentá veis da Améric a Latina e Caribe; Maria C. Correia, especialista líder em Desenvolvimento Social do Programa Especial de Pesquisa Agrícola da África; e Bernice Van Bronkhorst, consultora do Departamento de Finanças, Setor Privado e Infra-Estrutura da América La tina. A revisão do texto contou, a inda, com a colaboração da brasileira Isabel Ribeiro de Oliveira, professora titular do Instituto de Filosofia e Ciências Socia is da Universidade Federal do Rio de Janeiro. As informações recolhidas têm como base a revisão de literatura publicada e não-publicada sobre gênero no Brasil; revisão de estudos e projetos econômicos e setoria is financiados pelo Banco Mundial nas áreas de saúde, trabalho, pobreza rural e proteção social; da dos esta tístic os ofic ia is; visitas de campo por consultoras do Banco Mundial a projetos de desenvolvimento rural no estado da Paraíba; entrevistas com autoridades govemamenta is e acadêmicos; representantes da sociedade civil e de organizações de mulheres.

O livro está organizado em três partes: a primeira fomece uma visão geral das questões de gênero e as suas tendências; a segunda resume e disc ute as implic ações e as conclusões principa is coletadas pela pesquisa, em relação a seis índices - demográficos (1), de saúde (2), de educação (3), de mercado de trabalho (4), de pobreza e ajuste estrutural (5), e de política (6); e a terceira apresenta uma estratégia de continuidade e faz recomendações setoria is.

A segunda parte do livro, qua nto a os índices demog ráfic os (1) do Bra sil, mostra um qua dro em que o maior número de mulheres e de idosos, sendo a maioria de brancos, está concentrado nas áreas urbanas. Aponta a queda das taxas de fecundidade e de mortalidade e o maior controle da natalidade através do uso de métodos contraceptivos como fatores que contribuem para a alteração da pirâmide demográfica.

Em relação aos índices de saúde (2), são citadas as doençascardiovascula rese o câncer como as principais causas de morte entre os brasileiros. As autoras alertam ainda que os homens apresentam um número elevado de mortes por causas extemas, como acidentes de trânsito e conflitos com armas de fogo; já as mulheres, devido às característic as a na tômicofisiológicas específicas, são ma is vulneráveis à contaminação por doenças sexualmente transmissíveis. Alerta $m$ ta mbém pa ra o crescente número de casos de brasileiros/as conta mina dos/ as pela Aids e identificam que a doença vem se espalhando para além dos grupos tradiciona is de risc 0 .

Outro alerta é para o alto índice de mortalidade materna entre as camadas mais pobres da população devido à má qualidade da assistência à saúde das mães, caso de gravidez de risco e abortos em condições inadequadas. Pedem atenção especial às 
mulheres indíg enase às tra ba lha doras rura is que, expostas a situações de risco, têm recebido tra tamentos ina dequados. 0 excesso de consumo de álcool é outra questão preocupante, responsável por $90 \%$ das intema ções de homens em hospita is psiquiátric os e diretamente relaciona do a o aumento da violência doméstica.

Conforme dados do relatório, a violência no país está aumentando, com maior incidência dentro das residências. A violência doméstica pode ser classificada em dois tipos: a de adultos contra crianças; e a de homens contra mulheres, a mbas envolvendo subordinação e relações de poder. Segundo o relatório, os a dultos tendem a minimizar ruas a ções violentas contra as crianças justific ando-as em nome da "boa educação", o que contribui para a reprodução da violência em diversos setores sociais.

Homens e mulheres são afetados pela violência, criando uma bipolaridade de gênero públic o/privado. Os dados do rela tório informam que os homens tendem a ser ma is a ting idos por causas extemas e a tos violentos praticados por conhecidos ou por estranhos fora do âmbito familiar, enquanto as mulheres experimentam a violência dentro da própria casa, praticada pelos pais, por maridos (e ex) e pornamorados (e ex). Na maioria dos casos, não ocorre denúncia, exc eto em casos ma is graves que envolvem risco de morte.

O relatório denuncia também a presença de diversas rotas internacionais de tráfico de mulheres, principalmente de adolescentes negras, pardas e pobres em cidades costeiras. Quanto à população carcerária, há uma maior incidência de homens presos, seguidos por mulheres não-brancas e pobres.

Em relação a os índic es de educação (3), o documento chama a atenção para oscuidados que devem serdispensa dos no sentido de garantir a continuidade dos estudos a os homens, que tendem a abandonar a escola mais cedo. Por outro lado, cresce o nível de escolaridade entre as mulheres, que já se a presenta superior a o dos homens. Segundo o relatório, as mulheres preferem as áreas humanas e sociais, e os homens, as ciências exatas, associadas a representações tradicionalmente masculinas como objetividade, precisão de resultados e segurança. Essa preferência de homens e mulheres por certas áreas, conforme aponta o relatório, é reforçada pelos livros didáticos que reproduzem preconceitos de gênero. Destaca também a importância de maiores cuidados à organização de creches e à qualidade da educação pré-escolarque, não sendo prioridade do governo, ficam entregues a iniciativas individua is, com prejuízo para as camadas mais pobres da população.

No mercado de trabalho (4), uma nítida "socia lização de gênero" rege a distribuição de cargos, promoções e salários, limitando a a scensão feminina. Apesar dessa tendência, cresce o número de mulheres chefes de família. A dupla jomada de trabalho, um problema a ser resolvid o pelas mulheres ma is pobres, depende, segundo as informações recolhidas, da maior participação masculina na divisão das tarefas doméstic as, o que deixaria as mulheres ma is livres para o desenvolvimento profissional.

Conforme dados do rela tório, fa tores como etnia, idade e nível de escolaridade do chefe de família, o tipo de oc upação, as condições de trabalho e o número de crianças pequenas nos domicílios tendem a influenciar os índices de pobreza da população (5) brasileira. Os negros, chefes de família mais jovens e com menor escolaridade, os trabalhos informa is e os agrícolas, e mais que duas crianças pequenas porfamília, tendem a elevaro nível de pobreza. Em relação a o ajuste estrutural, quando as alteraçõesna macroeconomia afetam o setorda indústria, causam maior desemprego entre os homens e, quando atingem o setor de serviços, a feta $m$ mais as mulheres.

O desemprego aparece como uma das principa is causas de problemas rela tivos a autoestima, depressão, a lcoolismo e suicídio, principalmente, entre os homens, pois ameaça o papel de provedor que desempenham socialmente. 0 aumento do trabalho infantil masculino é um outro efeito da instabilidade econômica que necessita de maior atenção, sendo um dos motivos que levam meninos e meninas ao abandono escolar. Na política (6), a inda é tímida a participação feminina, embora os partidos sejam obrigados a destinar $25 \%$ de suas vagas a candidatas.

$\mathrm{Na}$ terceira parte desse rela tório, as autoras fornecem uma estratégia de continuidade e fazem recomendações setoria is a respeito dos trabalhos de gênero no Brasil. Tendo como ponto de partida a busca pela igualdade entre homens e mulheres, propõem estratégias sobre as questões de gênero que atinjam esse objetivo, nas dimensões referentes a saúde, violência, educação, trabalho, pobreza, flutuações econômicas e redes de proteção social. Desse modo, cabe aqui ressaltar a conceituação de gênero, proposta por esse documento:

é uma construção sociológ ic a rela tiva mente recente, respondendo à necessidade de 
diferenciaro sexo biológico de sua tra dição social em papéis sociais e expectativas de comportamentos femininos e masculinos, tradução esta demarcada pelas relações de poder entre homens e mulheres vigentes na sociedade (p. XVII).

Na dimensão da saúde reprodutiva, as autoras ressaltam a importância de "incluir a redução da taxa de mortalidade materna, rela tiva mente alta no Brasil, a melhora no acesso ao planejamento familiar para os ma is pobres e visar os homens como parceiros nos programas de reprodução e de sexualidade" (p. 153). Na saúde reprodutiva e sexual, desencorajam a esterilização como um método de controle de nata lida de, dado que ela pode levarà redução do uso da camisinha, permitindo a transmissão de doenças, entre outros aspectos. Também instiga m os epid emiolog istas a desenharmelhores programas de controle e prevenção da violência, da depressão e de comportamento de risco. Quanto à saúde dos povos indígenas, chamam a atenção para os grandes problemas pelos qua is passam esses grupos, e justificam a criação de um programa que diminua a taxa de mortalidade entre homens e mulheres, para a preservação da riqueza cultural que ta is grupos lega m a o Brasil.

Dando prosseguimento às dimensões, a violência é o item considerado prioritá rio para o trabalho relativo a gênero no Brasil, e o sistema educacional, os programas comunitários e a mídia são os principa is veículos para a prevenção da saúde. Nesse sentido, o relatório exalta os programas preexistentes no Brasil que tra tam das nec essida des dos meninose das meninas de rua em geral e, em particular, daqueles que vivem na prostituição.

No item educação, as a utoras fazem duas ressalvas: primeira, no sentido de tentar manter osmeninosna escola, impedind o que eles fiquem com índice de escolaridade inferior ao das meninas; segunda, para melhorar a qualidade geral da escola ao reduzir os estereótipos relacionados a gênero transmitidos pela educação. Recomendam investimentos em creches, contribuindo para a melhora no desempenho das crianças e possibilitando à mulher (mãe) tra ba lhar "fora".

Quanto às questões ligadas a o tra balho, as autoras do rela tório a firmam que o Brasil precisa tratar das diferenças sala ria is persistentes relacionadas a gênero. Outra prioridade é pesquisar se a lic ença-maternida de contribui ou disc rimina a inda ma is as mulheres no campo de trabalho. Sugerem que homens e mulheres possa m compartilhar a patemidade, o cuidado dos filhos e as ta refas doméstic as, com o objetivo de liberta ras mulherespara a ma iorparticipação na força de trabalho e no emprego.

Concluindo, as autoras revelam que a incidência maior de pobreza e vulnerabilidade está entre as famílias com crianças menores de cinco anos de idade, especialmente aquelas encabeçadas pormulheres. Poroutro lado, fazem duras repreensões aos modelos utiliza dos pelo Brasil para captar dados relacionados à indica ção do "cabeça" da fa mília, mostrando a inexatidão na descrição de lares típicos da América Latina. Citam, como um modelo a seguir, o exemplo do Banco Mundial realizado no México.

Apesar de objetivar a discussão sobre gênero, verifica-se que o relatório concentrou suas informações sobre as mulheres. Conforme recomendação das próprias autoras, fica a necessidade de um maiora profunda mento sobre características específic as dos homens e os efeitos de gênero sobre eles. Sugerimosque seria bastante válida a inclusão de uma análise em que as autoras pudessem conceituar e diferenciar, com maior precisão, os termos utilizados para a denominação da população não-branca: ora é utiliza do o termo "parda", ora "preta", ora "negra". Recomenda moso emprego da palavra "negra" porreferir-se a etnia, e não a cor, a fim de evitar uma possível conotação disc rimina tória.

Trata-se de um trabalho que documenta as questões de gênero no Brasil e que está a mparado em dadoscoleta dos poruma grande e fidedigna instituição, porém, observamos que as autorasainda a presentam a lguma cautela ao fazer recomendações estratégicas à continuidade de programas ligados a gênero. Nesse sentido, sugerimosque uma possível revisão desse documento acrescente ma is comentários em forma de uma análise aprofundada sobre os efeitos das representações socia is relativas a cada tendência a presentada. À luz de uma avaliação geral, o rela tório vem prestarum relevante serviço a os pesquisadores da área de gênero.

Sandra Bellas de Romariz
Universidade Gama Filho

Simone M. F. Gomes Universidade Salgado de Oliveira

Sebastiã o Votre Universida de Gama Filho 